International Journal of Forensic Science \& Pathology (IJFP)

ISSN 2332-287X

\title{
Doctors and Medico Legal Examination of Victims of Sexual Offenses
}

Khan MK

Assistant Professor, Department of Forensic Medicine \&Toxicology, JNMCH, AMU, Aliagrh, Uttar Pradesh, India.

\begin{abstract}
This increasing incident of crime against woman is adding up to the number of female patients. This, along with normal female patients there is a dire emergency in the treatment of female victims of sexual assault. We need provision in our hospital set up to treat the victims separately. There is also an awareness campaign against the sexual crimes and the right of women. Thus increasing trend of crime against woman in India is also burdening the health system in providing treatment and medico legal work.

There are various steps in the general examination where the female patient though gives the consent, but do not welcome the moves of the doctor. This feeling often makes the patient uncomfortable and may compel the patient herself or relatives to bring charges of indecency and of sexual assault against the doctor. The casual attitude of doctors is not going to stand in the present scenario. There has to be strict and vigilant environment in our hospital as far as dignity and privacy of female is concerned. Woman friendly environments and attitude should reflect in our hospital.
\end{abstract}

Keywords: Rape; Medico Legal; Criminal law.

\section{*Corresponding Author:}

Dr. Mohd Kaleem Khan,

Assistant Professor, Department of Forensic Medicine \&Toxicology,

JNMCH, AMU, Aliagrh, Uttar Pradesh, India.

Tel: 8053450316

E-mail:khan4uat9@gmail.com

Received: April 25, 2015

Accepted: April 29, 2015

Published: June 04, 2015

Citation: Khan MK (2015) Doctors and Medico Legal Examination of Victims of Sexual Offenses. Int J Forensic Sci Pathol. 3(6), 136-138. doi: http://dx.doi.org/10.19070/2332-287X-1500032

Copyright: Khan $\mathbf{M K}^{\odot}$ 2015. This is an open-access article distributed under the terms of the Creative Commons Attribution License, which permits unrestricted use, distribution and reproduction in any medium, provided the original author and source are credited.

\section{Introduction}

It has been observed that the crime against woman is rising in the country and it also respects the data of the National Crime Records Bureau (NCRB) that 33,707 females were raped in 2013 as compared to 24,923 in 2012. It also shows that around 93 women are being raped every day [1].

Sexual assault is itself such a heinous crime that any of punishment is not sufficient to replace the damage that has been caused. The physical trauma heals, leaving behind the long term psychological trauma.

This increasing incident of crime against woman is adding up to the number of female patients. This, along with normal female patients there is a dire emergency in the treatment of female victims of sexual assault. We need provision in our hospital set up to treat the victims separately. There is also an awareness campaign against the sexual crimes and the right of women. Thus increasing trend of crime against woman in India is also burdening the health system in providing treatment and medico legal work.

As the new law against sexual offenses (The Criminal Law Amendment Bill, 2013) [2] defines and cover almost all aspects of crime against women. The new definition of rape [2] (Section 375 IPC) as per (The Criminal Law Bill, 2013) now includes even touching and manipulating genital organ, including the urethra and anus either by hand or any other object. With the amendment of the existing laws of sexual assault and rape, there is a great protection to the females in India. This law not even covers the simple act violence of against the female body, but even the smallest gesture that is leading to obscenity. Section 354 IPC4 Now in all its section cover almost all the aspect assault of females that are sexual in nature.

Different sections of IPC 354 [2] cover sexual advances, showing pornography, making sexually colored remark, disrobing the female, capturing images or watching the female engaged in private act and stalking. Section 354 [2] has been often used against the doctors who are examining the patients in the process of making the diagnosis, treatment and follow up. Though consent and examination of the female are obtained, but it does not guard the doctor from the charges being brought upon under many sections of the law. There are various steps in the general examination where the female patient though gives the consent, but do not welcome the moves of the doctor. This feeling often makes the patient uncomfortable and may compel the patient herself 
or relatives to bring charges of indecency and of sexual assault against the doctor.

The casual attitude of doctors is not going to stand in the present scenario. There has to be strict and vigilant environment in our hospital as far as dignity and privacy of female is concerned. Woman friendly environments and attitude should reflect in our hospital. This wide coverage of definition of rape has not given a proper guideline about the medical procedures and treatment. (Explanation 1 Sec. 375IPC[2]) leading to vulnerable exposure of doctors to litigation and charges brought against them. Section 354 [2] especially does not mention the exception to the doctor's treatment, counseling, rehabilitation of the female patients.

Various points of worry with dealing the female patients may come in different stages of the procedure and treatment.

History taking may become objectionable with one of the following conditions

- Asking about development of secondary sexual character

- Detailing the history of the menstrual cycle of a female.

- Inquiring about the sexually transmitted disease of a female.

- Asking about past sexual activity from female.

\section{Demonstration and Counseling}

- Showing photograph of different stages of development of breast and changes due to pregnancy to a female.

- Showing a photograph of genital development and other abnormalities may be objectionable.

- A woman may find awkward the demonstration of different modern techniques and treatment like self-examination of breast, palpation of lump in the breast.

- Instructing females for self medication of pessaries and enema may be felt embarrassing.

- Reminding females about checking threads in IUD and demonstration of the use of female condoms may not be taken in easy way.

- Uneasy feeling to demonstration of physiotherapy exercises, especially to post partum females.

- Demonstration of examination techniques to the students under training program as well as academic examination, seminar and conferences

- Procedure adapted during artificial insemination may not be taken in healthy spirit.

Doctor needs extra precautions in language and attitude. All this makes male doctors vulnerable to be charged under different sections of IPC 354 [2] as per the Criminal Law Bill, 2013*.

- Touch by male doctors to a female patient can be charged 354 A (1) (III) [2]

- Exposure of the breast for examination either by the patient herself on demand of doctor or with the help of the attending nurse may make the patient uncomfortable (354B) [2]. Patients may allege the disrobing her.

- Exposure of the private parts for inspection again falls in the same category. 354A (I) (III) [2]

- $\quad$ Forceful exposure (disrobing) 354B [2]

- Watching (seeing) private parts 354 C [3]

- $\quad$ Physical contact 354A 1 (I).

- Use of technology in examination like endoscopic visualization and showing on the monitor again make the doctor to come in the ambit of IPC 354C [3] allegation.

- Demonstration, teaching and visualization on monitor to medical students and in conferences and symposium again may lead the doctors in patient and their relative discomfort able and they may allege charges of sexual assault. 354C [3]

Under the new amendment in IPC 375 [2] the Criminal Law Amendment Bill, 2013 even the slightest manipulation of the female genitalia amounts to rape.

- Per vagina examination either by hand or with the help of instruments.

- Examination of urethra of female.

- Per rectal examination of female either by hand or instrument.

These all procedure can attract charges of rape if proper care for consent and privacy is not taken.

\section{Requirement of a Good Consent Taking Ability}

Most of the doctors carry out most of the work under the common feeling of implied consent which is dangerous now days. Though implied consent is equally valid, but its limits have not been defined by the law so one should avoid examination above from very basic under this consent.

A detailed informed consent should be taken in all aspects of female examination and treatment. All the aspects of informed consent should be cured carefully.

Mental stability and capacity should be checked along with full disclosure of the procedure, in the last patient should be allowed to give consent with free will [4].

The basic nature of the medico legal examination should be explained to the victim. It includes the proper history taking of the current incidents in the past sexual history. Detailed description of examination and evidence collection should be given and should also be explained about the benefit of proper history $\&$ examination in court and what could stand against or in favor for her.

Consent should not be forced, but patients should be reminded about the loss of the evidence in delayed or not having examination done.

Medico legal examination of female victims if done under $\mathrm{CrPC}$ 164A [5], which gives the permission to the male doctor to examine the victim of sexual assault on the request of the inquiry officer if the victim's consent to do so.

Proper consent and then history and examination should be done in the presence of an attendant. Proper care is required is nothing the particular of victims and signature and thumb impression is mandatory in the consent form.

\section{Discussion}

Help to the victim of sexual offenses is mandatory and that require a lot of expertise and care. The infrastructure available for the medico legal work is very poor and to maintain quality and care in that is quite a tedious job. This poorness of infrastructure 
does not decrease the liability of the doctors and also do not protect doctors against negligence charges brought up against them. Recent amendments in the criminal laws compel the hospitals either public or private and either run by the central government or state government (357 CrPC) [2] to attend the victim of a sexual offense (IPC 376) and acid attack [2] (IPC 326A) immediately and provide all the medical attention required and informed the police immediately any deviation from this rule (357CrPC) warrant punishment under section IPC 166B [2].

Further Supreme Court declared all the medico legal examinations of victims of rape as an emergency. In its judgment (2000) [6] the apex court also gave priority to treatment than an examination. This judgment clears the air from the very, often argument of medico legal examination before commencing treatment. So the doctors should emphasis on treatment first if there is any delay in the medico legal examination of the victim. This ruling also gave the victims consent more importance our section 39 CrPC (mandatory information to the police) [7]. Thus the victim of sexual assault may present in either way.

- Voluntary reporting by the victim;

- Reporting on requisition by the police, and

- Reporting on requisition by the court

Consent is also required for the victim to intimate the police as there is no compulsory provision to inform the police. The whole and sole decision about informing the authorities about the incident should remain with the female victim, although in section 39 Cr PC doctors are bound to inform proper authorities about the assault against women (498A) [8] but it does not have any mention about the victims under on 354 or 376 IPC.

Unfortunately, this information has not been well communicated and understood and the to all doctors still insist on a police requisition before examining a rape victim.

The liberal reading of the section $53 \mathrm{CrPC}$ [9] in which it says that only female registered medical practitioner working in a government set up can only examine the victim of sexual offenses in the presence of a female attendant is causing great problem to the victims. Especially in those areas the country where we have poor infrastructure and scarcity of the female doctors or overburdened single female doctor leading to further trauma to the victim and also a loss to the justice system as many important evidences are lost due to delay and improper handling.

Further, it has been elaborated in section (164 A CrPC) that the male doctor to examine the victim of the sexual offenses if the female gives consent to do so. The allopathic doctor, registered under MCI can perform the medico legal examination at the request of the inquiring officer in the presence of a female attendant and preserving all evidence.

This ruling is most of the times is ignored or non awareness among police personnel and also the doctors are adding unnecessary trauma and delay to the female victim of sexual offenses. There should be a thorough campaign among the police personnel and doctor regarding this law.

New amendments in IPC 354 clearly gives the widest coverage against the crime of sexual advances and assaults against women in different prospects, but it did not mention any safeguard to the doctor treating the patients. Though it is clearly understood that treatment of is done under the consent, but the discomfort of the female may attract the changer against the treating doctor.

Once again, not to forget that the Delhi High Court clearly the health authorities and the attending doctor that the medical examination of victims of rape should be performed in a separate room designated for it and also specially mention the use of the SAFE Kit in the examination [10].

Past history regarding sexual activity of the female has been always part of the scrutiny of the character of female bringing disrespect to the integrity of the female. Therefore new amendment 2002 in The Indian Evidence (Amendment) Act, [11] prohibits the questions being asked about the past sexual history in cross examination.

However, a medical practitioner conducting an examination of a victim of rape often requires information about her past sexual acts, intercourse and sexual practices. This is to correctly interpret the physical and genital findings on the victim, the findings (injuries sustained) of a forceful sexual act in a virgin person (who has not experienced sexual intercourse) differ from those of a person who has experienced sexual intercourse in the past. Before this information is collected, the doctor must properly explain the victim purpose of collecting this information and how it would help in her case to obtain justice by properly interpreting the physical and genital findings (the injuries sustained). She must also be explained the amendments of section 155 IEA, [12] otherwise the victim of rape may be hesitant to part with this crucial information, as she will believe that this information, once given in the medical records, may be used against her by the defense lawyer.

\section{Conclusion}

1. Special precaution should be taken in examination of a female patient.

2. Victims of sexual offenses treated with extra precaution and care.

3. Consent of female victims of sexual offenses should be given superiority over other legalities.

4. Extra emphasis should not be laid on section $53 \mathrm{CrPC}$ in examination of female victims.

5. Liberty given in section $164 \mathrm{~A}$ CrPC should be given priority over section 53 CrPC.

\section{References}

[1]. National Crime Records Bureau (NCRB), crimes in India (2013), Crime Against Women

[2]. The Criminal Law (Amendment) Act (2013) http://indiacode.nic.in/actsin-pdf/132013.pdf

[3]. The Criminal Law (Amend) Act (2013) http://indiacode.nic.in/

[4]. Khan MK, Hanif SA. Self Autonomy and informed consent in clinical setup (2010). Indian J Med Sci 64: 341-8

[5]. The Criminal Law Amendment Act (2006) http://www.ncw.nic.in/

[6]. Supreme Court of India.(2000) Judgments, the judgment information system of India. State of Karnataka v. Manjanna (6): 188

[7]. Public to give information of certain offenses. (1973) The Code of Criminal Procedure, (CrPc) http://www.vakilnol.com

[8]. Husband or relative of husband of a woman subjecting her to cruelty. Section 498A. Indian Penal Code (IPC) 1860. http://www.vakilno1.com

[9]. The Criminal Law Amendment Act 2006, CrPC 53. http://www.ncw.nic.in/

[10]. High Court of Delhi (2009) Delhi Commission for Women v. Delhi Police, W.P (CRL)696/2008 http://www.ncw.nic.in/

[11]. Indian Evidence (Amendment) Act (2002) http://www.commonlii.org/

[12]. Supreme Court of India. Judgments, the judgment information system of India. (2000) State of Karnataka v. Manjanna (6): 188. 